\title{
The application of resilience planning concepts as a tool for Assessment and evaluating Egyptian urban communities to achieve resilience after disasters
}

\author{
Said H. Al-Sayed, Doctor at Thebes Academy- High Engineering institute, Egypt \\ Yousef A. ElSayed, Doctor at Thebes Academy- High Engineering institute, Egypt \\ Sahar S. Gadou, Doctor at 6 October University - Faculty of Engineering, Egypt
}

\begin{abstract}
After the revolutions of the so-called Arab Spring which begin in Egypt at January 25, 2011, many disasters occurred in many Egyptian cities, and also significant changes in cities led to the emergence of severe shocks suffered by the community, including other subversive threats as Corona pandemic, long-term social pressures like unemployment and poor access Barriers to education, crime or homelessness, as well as deliberate sabotage of urban structures and infrastructure, directly or indirectly, have led to the deterioration of cities and the change of human behavior for the worse.
\end{abstract}

The research aims to identify the concepts and methodology of resilience planning, and apply them to Egyptian cities to increase its ability to recover and adapt positively to un expected changing circumstances or challenges, including Revolutions, Corona pandemic, disasters and climate change, to maintain quality of life and healthy growth, and to achieve permanent systems that can preserving resources for present and future generations. It will also aim to create a tool as (Cities resilience assessment form) for assessment and evaluating the Egyptian Cities for its resilience. That will help to make a community resilience plan includes policies, programs and other actions that can be taken in many sectors to improve a society's ability to cope with risks or change circumstances. Resilience planning can thus reduce future disaster response and recovery costs and improve recovery time after natural or human hazards events.

The research will include the definition of resilience planning concepts, implications and objectives that aim to update flexible land-use codes, zoning, development criteria, incentive programs, and other plans or policies to better prepare for potential shocks and pressures, and also help to develop standards that allow action against unexpected events.

\section{Keywords}

resilience planning concepts, Disasters, Sabotage and destruction of cities, Development criteria, Disaster response measures

\section{Introduction:}


The resilient city is one of the modern planning terms for cities that appeared at the beginning of the twenty-first century, especially after cities and urban communities were exposed to many devastating natural disasters such as earthquakes, volcanoes, floods, rising sea levels and the exacerbation of global warming. Natural disasters were not the only ones affecting the city, but there are human impacts that accumulated over a long period of time, which led to the deterioration of city urban mass and the poor quality of life in it with the emergence of deficiencies in its facilities and services.

Resilience means the ability to recover quickly from disasters that happen suddenly. Planning for resilience in such place means the strategies that you plan in order to fight unexpected disasters such as a sudden shortage of human resources, assets, or anything else. Preparing to reduce risk is the most that can be done as part of resilience planning. The right resilience procedure helps planning processes through resilience management to prevent disaster. With the help of tools such as efficient and streamlined technology for basic in-place procedures. Urban resilience has gained greater importance over the past decade in international development discourse and has emerged as one of the basic principles of sustainable urban development in global development frameworks and goals, including conference of Sustainable Development Goals, a new urban agenda, as well as the Paris Agreement on climate change, in addition to the Sendai Framework for Reduction. Disaster Risk 2015-2030.

\section{Resilient cities:}

Resilient cities were defined by several definitions, the most accurate of which is that it is the city can live after being exposed to disasters, and quickly return to its normal position (before the disaster). Habitats have defined resilience city as the city that have the measurable ability of any urban system, along with its inhabitants, to maintain continuity through all shocks and stresses, with positive adaptation and a shift towards sustainability. Faced with risks from earthquakes to floods, rapid migration to cyberattacks, all cities face a combination of shocks and stresses, both natural and man-made. Today, urban and urban residents face additional and amplified challenges as a result of rapid urbanization, climate change, political instability, and many other things.

The resilient city was also known as the city that accommodates the activities and residents and interacts with the current conditions and is formed to deal with any future activities and risks that may pass through. Through this, resilient cities are defined as being more capable of protecting and enhancing people's lives, securing development gains, and promoting an investable environment and positive change. Three major dimensions of resilient city structure that are governed by effective leadership and strategy, sharing stakeholder authority to put integrated planning (Figure -1)- They include: -

- Health and well-being of everyone who lives and works in the city.

- Financial and Society systems that enable city dwellers to live in peace and work collectively.

- Infrastructure and Environment which means what man-made to provides basic services. 


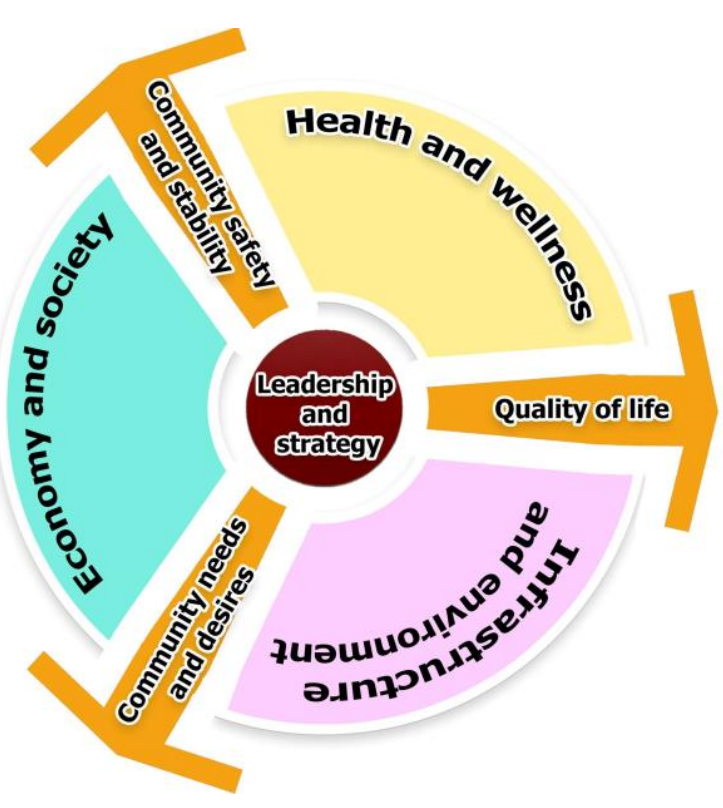

Figure 1. The main dimensions of urban structuring for urban resilience

A set of standards and specifications have been developed to achieve the characteristics of a resilient city through research carried out by some institutions, including the following:

Reflexive and resourcefulness: it means learning from the past and acting in times of crisis. Individuals and organizations reflect the experience of using the past to inform future decisions, and adjust standards and behaviors accordingly. This makes planning processes more responsive to changing conditions. As for the resourcefulness of people and institutions: it is the ability to find alternative ways to use resources in times of crisis in order to meet people needs or achieve their goals.

Durability, Repetition and Flexibility: These are the qualities that help visualize systems and assets that can withstand shocks and stresses as well as the willingness to use alternative strategies to facilitate rapid recovery. Robust design includes adopting and managing arrangements in place to ensure failure is predicted, safe, and proportionate to the issue. As for redundancy, it refers to the reserve capacity that has been intentionally created to absorb the damage that has occurred due to severe pressures, such as storms or an external event, and it includes diversity where there are multiple ways to achieve a specific need, for example, power systems that incorporate redundancy aim to provide multiple conduction paths that can accommodate surges in demand or disruptions to network supplies. While flexibility is concerned to adopt alternative strategies such as responding to changing circumstances or sudden crises, through systems that can be more flexible by introducing new technologies or methods of knowledge, that including the recognition of traditional practices. For example, in times of crisis, cities can reassign public buses for emergency evacuations.

Inclusiveness and Integration: It relates to good governance and effective leadership processes that include appropriate investments and standards to meet the needs of the most vulnerable groups and to create a flexible city for all. Inclusivity emphasizes the need for broad consultations and "lots of seats at a table" to create a sense of shared ownership or a shared vision for building resilience in the city, This helps to achieve early warning of danger to all, enables people to protect themselves and reduce loss of life and property. Complementarity is concerned with cooperation between people and different 
agencies (each according to his potentials and capabilities) to activate the required tasks of all groups of society under rational leadership.

\section{Resilient cities and types of disasters}

\subsection{Types of disasters that cities are exposed to}

There are many natural hazards and dangers caused by humans, and the so-called natural disasters are often the result of latent factors that originate from the earth or from the sky and are often caused by human activities that are incompatible with nature, such as building in areas subject to floods, cutting trees, or the construction of buildings on fragile lands or soils subject to swelling, or that were carried out without engineering studies and not taking into account safety standards, and here are some of the most common hazards that may lead to disasters according to the studies of the World Meteorological Organization; And the International Science Council, 2007 (WMO, ICSU)- figure (1):.

- Climate hazards: tropical cyclones, heat waves, fires - lightning and torrential rain.

- Dangers of climate change: increased frequency and intensity of storms, glacial lake flooding (occur when dams collapse Containing a glacial lake).

- Hydrological hazards: floods in rivers or beaches, flash floods and tsunamis, and suitable high seas and oceans.

- Geological hazards: volcanoes, earthquakes, and massive movement of land masses (waterfalls, slides, and landslides).

- Astrophysical hazards: meteors and meteors.

- Biological hazards: epidemics and pests.

- Human risks: armed conflict, fires, pollution, collapse of infrastructure, civil unrest and terrorism, in addition to the piles of waste and rubble resulting from human and construction waste.

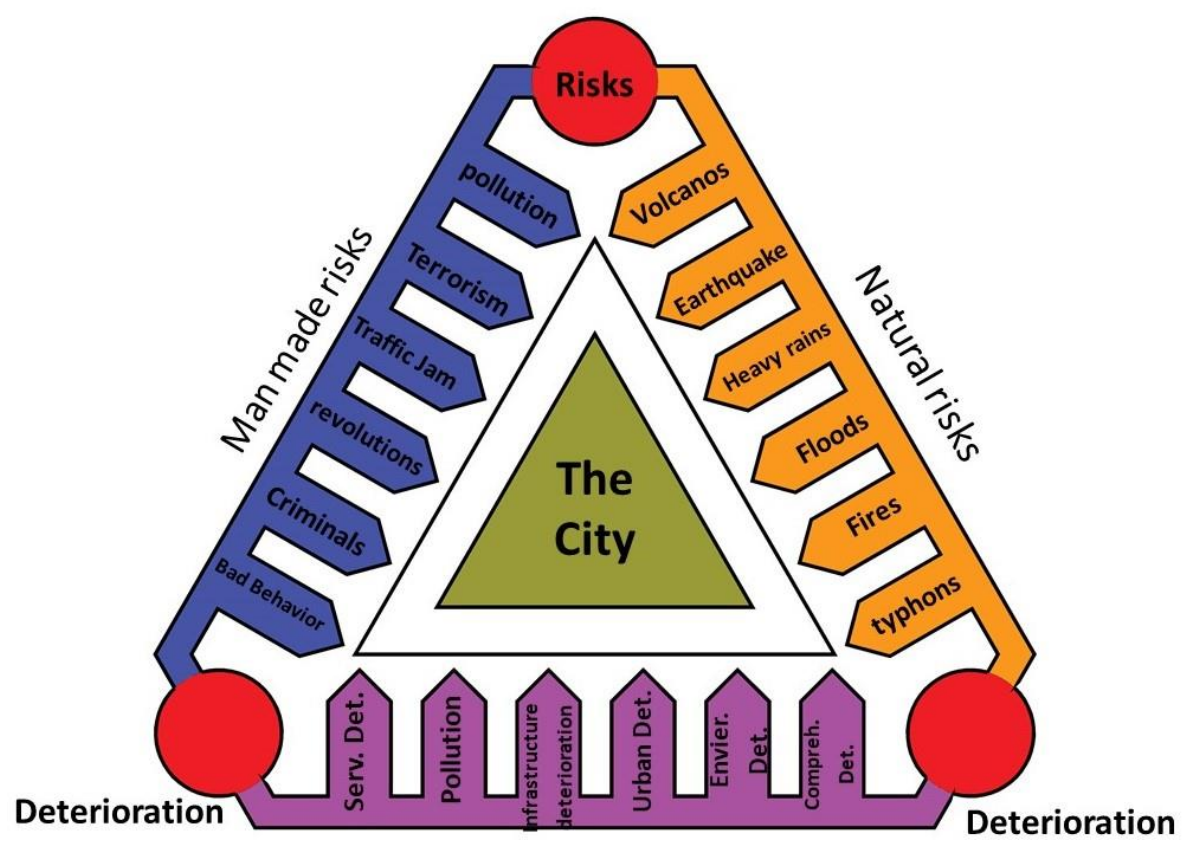

Figure No. (2) Types of risks and their impact on cities 


\subsection{The impact of natural and human hazards and disasters on cities and urban agglomerations}

The natural and human disasters in the past few years have caused a great loss in urbanization of cities and communities. The earthquake that struck Egypt in 1992 caused the collapse of thousands of residential and service buildings, the loss of thousands of people, cracks that affected many important heritage, and the floods that occur with the onset of winter on coastal cities such as Arish And Dahab and some cities in Upper Egypt that lost many buildings and destroyed many utility networks, cutting off the roads leading to them. All this led to complete paralysis. And the heavy rains that fell in the winter of 2019 on some new cities east of Cairo, which also led to traffic problems that reached for several days because they led to the collapse of some roads and filled the tunnels with water. Natural disasters happen to most countries of the world, and of different types, for example, the earthquake that struck the city of Bam (in Iran) in 2003, the fire that broke out in the old city in Edinburgh) United Kingdom (In 2002, sabotage and armed conflict that caused the destruction of large Buddha statues in Bamiyan, The Sacred Tooth Temple was destroyed in Sri Lanka due to a terrorist attack in 1998, and in 2007 Cyclone Sundarbans destroyed orchards of tropical mangrove trees, drowned fishermen and ruined wildlife due to salt water intrusion in Bangladesh. Also, the climatic cycles that cause natural phenomena such as the El Nineo phenomenon that in turn control with cycles of drought and floods in different parts of the world, the potential for hazards in protected areas may increase if combined with disturbances at sea level due to climate change.

Hazards are events that change, weaken or destroy the valuable aesthetic elements.

\section{Planning methods for implementing resilient cities}

\subsection{Resilience planning method}

There are many thinkers and planners who have begun planning the new city for the sake of resilience, especially in some countries that are exposed to frequent dangers such as Japan earthquakes and river floods in some countries such as Sudan and landslides, and the planning steps for resilience have been reduced to eight steps as follows:-

- Forming a cooperative planning team: it includes identifying team members and their leader, main stakeholders, as well as defining the role of each member and the different groups of society.

- Study of the social dimensions: by selecting and distinguishing the social function and dependencies and determining the support from the built environment as well as the main contacts.

- Study of the built environment: including determining the city mass and identifying the main points of contact and determining the plan of influencing communities.

- the link between the social function and the built environment: It begins with the study of its uses and urban characteristics with linking the mass uses and activities data to the social and economic characteristics of the population.

- Defining goals and objectives: setting long-term societal goals and setting performance goals in addition to identifying community risks and determining performance to address those problems, as well as an executive summary of tasks and steps and reaching the expected result.

- Setting a development plan: to achieve flexibility, assessing gaps, identifying problems, identifying solutions and alternatives, developing an implementation strategy.

- Preparing, reviewing and approving the plan: documenting the plan and strategy, obtaining feedback and approval, finalizing the plan, adopting the plan and approving.

- Implementation and maintenance plan: implementing approved solutions. Evaluating and updating the disaster management plan, modifying the strategy as needed 


\subsection{The City Resilience action plan RAP and frame work plan RFP}

There are also other types and approaches for flexible planning that correspond to the size of the gatherings and the levels of planning, including: -

a- RAP is a Tool methodology enables the delivery of high-quality, innovative and interactive training courses to help build and strengthen capacities of both communities and decision-makers in disaster risk management, climate change adaptation and urban resilience. Two types are available:

- The City RAP Tool training of trainers' program, which provides tailor-made training courses adapted to local realities. After completing the training, participants are enabled to carry out training workshops themselves, and can use participatory planning and vulnerability assessments.

- A team of external trainers' kicks-off the process and supports it throughout each phase. A small group of at least three people should be trained to lead the process at the city level, hereafter referred as the Municipal Focal Points. They play a very important role as collecting data, supporting data analysis, facilitating discussions, ensuring effective communication with partners/stakeholders, actively engaging with communities through participatory approach, and drafting the City RFA.

b- RFA is a key document guiding decision-makers to improve city resilience and reduce risks. It identifies relevant challenges, priorities and actions to be implemented according to the real context. It can also be used as strong fundraising instrument for financing priority actions.

c- Many organizations as DiMSUR supports resilience planning and the development of RFAs in many municipalities as Chokwe (Mozambique), Zomba (Malawi), Moroni (Comoros) and Bissau (Guinea Bissau). They offer demand-led technical assistance providing different stakeholders with the expertise needed to promote urban resilience, manage disaster risks and adapt to climate change, and they work hand-in-hand with beneficiaries to develop locally appropriate solutions tailored to specific needs.

\section{Resilient city relationship with residents' needs, and quality of life elements}

There are needs for basic elements for urban dwellers, including housing and community services of all kinds, and their minimum standard rates, and the higher the quality and efficiency of these elements, enhance resident's quality of life, and these elements include:-

Housing: where it must be a healthy dwelling, and achieves thermal comfort, and these requirements must cover all levels of housing.

Services: where the necessary services must be available including health, education, and other services. They must have the appropriate efficiency and compatibility with the requirements of the segments of society, and these services have rates and standards according to the planning level.

For Egypt, in order to achieve the requirements and desires of society, a code of quality of life is being created for the Egyptian citizen in the various urban communities. 
Utilities: it includes the provision of drinking water and sanitation services, electricity and communications which considered the most important elements that affect the lives of people.

Urban spaces: It help in practicing social activities and political gatherings, various celebrations on holidays and occasions, and whenever these spaces exist it increases the quality of life.

Green areas and parks: green spaces contribute to raising the efficiency of the city urban environment, as it contributes to improving the characteristics of the climate, it give psychological comfort to the inhabitants around or near it, and encouraging meetings between them, It also contributes to making the people healthier.

Transportation and roads: Peoples require a good transportation network suitable to meet their requirement's mobility, and the efficiency and quality of these types depends on their condition, efficiency and diversity, in addition to the places of their distribution within the city and their relationship with Population concentrations, service and economic activities.

The urban mass condition: Sometimes there is enough of the aforementioned elements, especially housing and services, but they are not in good condition, as they lack durability or have not been built or finished, and also have not been furnished in an appropriate manner that makes them perform their role to achieves the quality of life, and this appears today in People have random or even informal areas, and there are fast-growing cities in which these problems appear (such as the spread of random areas in Cairo after the October War (1973).

\section{Critical cities and cities with the least resistance to disasters}

There are many cities that have the minimum requirements that achieve and meet the needs of the population, but they are not suitable for exposure to any risks, as they are more vulnerable to destruction and collapse when the risks occur. Rapidly growing and unplanned cities, they are more likely to collapse after a shock because they often suffer from pre-existing stresses and recurrent crises, they are often unprepared or unable to recover after the occurrence of disasters, that create a series of negative impacts, which endangers the city's jobs, exposes people to danger, and brings the city closer to the random phase. They are often uncontrolled, which weakens them and reduces the efficiency of their urban and economic components in addition to the failure of community services to serve required population.

The increase and strength of risks and their impact on cities and urban areas has a strong relationship with the increase in their population. The unplanned cities often suffer from deficiencies in educational and health services and other services, a lack of green areas and urban spaces, in addition to the deterioration of the state of urbanization and the lack of adequate housing, especially for the low social levels who suffer from Unemployment, poverty, marginalization, high population densities and urban congestion, the poor condition of roads, transportation, many utility networks, and waste collection network.

Many residents of those cities and urban agglomerations have shortcomings in quality of life standards, it affects behavior especially poor peoples, discrimination against strangers and women, and increasing crime rates, but often there is cooperation between them during risks. These citizens also suffer from social problems, which fast the decline in urban conditions, and their cities not able to bear any disasters or risks. 


\section{Applying the resilience cities methodology to one of the existing Egyptian cities}

By identifying the basic needs of the population in urban communities, as well as the elements of quality of life that were mentioned previously, an evaluation form was formed including the basis of which the city or urban grouping would be evaluated and its ability to be a resilience city, the following table clarifies those elements as well as the process of evaluating the communities based on City Specifications and Elements. Through the table, each sub or basic element of the city can be evaluated and its compatibility with the city's resilience specifications, A standard weight is also determined to measure the extent of the element's importance to citizens, the table also determines the maximum standard weight of the elements to be 100 degrees, and to be distributed on the evaluation scale in proportions of $80-100 \%$ of the degree when resilience, $60-80$ in equilibrium, $40-60 \%$ in case it is in the critical phase, $20-$ 40 in case it is fragile, and less than 20 in case of deterioration or onset of collapse.

The following weights have been assumed for each basic element such as housing, services and utilities 100 degrees, green areas 80 degrees and spaces 75 degrees, either the urban status is also 100 degrees, the social status 80 degrees, the economic 75 degrees, as well as management and governance to be 80 degrees as well, and the previous table is applied to the Resilience Diagram (Form) which contains the basic guidelines for achieving the resilient city, and thus there is a clear assessment of the elements in the city based on their fulfillment of the requirements of the resilience city,

This gives a clear image of the problems facing the city and every component in it, as well as giving more accurate and clearer perceptions to address the deficiencies. For example, if there is a problem with the availability or efficiency of services, the evaluation point appears far from achieving the characteristics of the flexible city, which gives an indication that the city needs to provide some deficient services or raise its efficiency. (Figure 2).

\section{Disaster risk management for Egyptian urban communities}

For the city to be resilience, it must have a management of the city's capabilities, they must have the expertise and the competencies to achieve the required resiliency characteristics through a good reading of the city and its elements, as well as the characteristics and people needs, they have a wide knowledge of the risks and disasters that the city is likely to encounter and can developing a plan to manage the city against disasters and risks.

There are three main stages in disaster risk management begin with the pre-disaster stage, which include the preparedness measures that must be taken before a disaster strikes, such as: risk assessment, mitigation measures for specific risks, and prevention (maintenance and follow-up, and preparation of various disaster management policies and programs). Contingencies that should be taken before a disaster strikes include measures such as establishing an emergency team, developing a plan and defining evacuation procedures, installing early warning systems, developing periodic training plans (such as evacuation training, for example), and providing temporary storage.

During a disaster, which is the period of the occurrence of the event, various emergency response measures should be taken to save the people and the city's capabilities, and the site's operators should have been trained to implement these measures during the emergency preparedness phase. Activities undertaken after a disaster include assessing damage and losses and remediating the elements that were 
damaged by carrying out repairs, restoration and retrofitting operations. And the plan, during the occurrence of the disaster, is to try to reduce the damage as much as possible, while focusing on guidance and direction in the local language for the residents of the urban community or city in order to save their lives and capabilities.

After the disaster, the phase of recovery/ risk prevention, rehabilitation and mitigation of its effects, preparedness and preparedness for emergencies, risk assessment, procedures for responding to remedial emergencies (such as repair, restoration and reconstruction).

As for the existing cities, a planning methodology can be followed, that begins with evaluates the elements of the aforementioned city and transforming it to a resilience city, as follows:

- Study of the current state of the city: It includes studying its environmental, urban, social and economic condition.

- study of the risks: This is done by studying the history of the city's or region exposure to and that may affect the city.

- Evaluating the city and its components based on resilience criteria.

- Determine the basic guidelines for achieving resiliency.

- The formation of an urban resilience department, including risk and disaster management.

- Developing an operational resilience plan.

- Establishing and activating the implementation tools and their management.

- Developing resilience plan review indicators.

- Implementation, monitoring and evaluation.

\section{Application of the resilience methodology to (San Al-Hajar city-Egypt)}

The city of San Al-Hajar is located in the Sharika governorate, next to an important archaeological area (Tanis), and its area is currently about 484 acres. This city had a strategic plan made in the beginning of 2016 after it was transferred from a village to a city at 2013. The adoption of the urban space for it in 2017 so that the space of the space is 555 acres. Table (1)

\begin{tabular}{|c|c|c|c|c|}
\hline \multirow{2}{*}{ Land use } & \multicolumn{2}{|c|}{ Area 2016 } & \multicolumn{2}{c|}{ Area 2032 } \\
\cline { 2 - 5 } & Fed & $\%$ & Fed & $\%$ \\
\hline Housing & 153.98 & $31.79 \%$ & 243.7 & $43.90 \%$ \\
\hline Mix. Housing & 30.58 & $6.11 \%$ & 35.48 & $6.39 \%$ \\
\hline Education & 9.54 & $1.97 \%$ & 24.66 & $4.44 \%$ \\
\hline Health & 0.64 & $0.13 \%$ & 3.16 & $0.57 \%$ \\
\hline Religious & 2.19 & $0.45 \%$ & 4.17 & $0.75 \%$ \\
\hline Sports - recreational & 5.04 & $1.04 \%$ & 5.04 & $0.91 \%$ \\
\hline Commercial & 5.55 & $1.15 \%$ & 10.1 & $\% 1.82$ \\
\hline Other services & 15.24 & $3.16 \%$ & 16.35 & $2.94 \%$ \\
\hline Industry - Crafts & 0.61 & $0.29 \%$ & 36.12 & $6.51 \%$ \\
\hline
\end{tabular}


Al-Sayed, S.H.;

ElSayed, Y.A.;

Gadou, S.S.
The application of resilience planning concepts as a tool for Assessment and evaluating Egyptian urban communities to achieve resilience after disasters

\begin{tabular}{|c|c|c|c|c|}
\hline Utilities & 6.81 & $1.41 \%$ & 6.94 & $1.25 \%$ \\
\hline Stop Station & 0.19 & $0.04 \%$ & 1.71 & $0.31 \%$ \\
\hline Vacuumed land & 39.6 & $8.18 \%$ & 0 & $0.00 \%$ \\
\hline Water Lines & 22.08 & $4.56 \%$ & 19.74 & $3.56 \%$ \\
\hline Agriculture Pockets & 45.62 & $9.42 \%$ & 0 & $0.00 \%$ \\
\hline Roads & 142.36 & $29.39 \%$ & 144.46 & $26.02 \%$ \\
\hline Cemetery & 3.55 & $0.73 \%$ & 3.55 & $0.64 \%$ \\
\hline Projects Land & 1 & $0.21 \%$ & 0 & $0.00 \%$ \\
\hline Total Area & 484.36 & $100.00 \%$ & 555.18 & $\% 100.00$ \\
\hline archology & 534 & & 534 & \\
\hline Total Area with Archology & 1018.4 & & 1089.18 & \\
\hline
\end{tabular}

Table 1. the existing and proposed Budget (2032) for San El-Hagar city

\begin{tabular}{|c|c|c|c|c|c|c|c|c|}
\hline \multirow[b]{2}{*}{$\underline{\underline{\underline{a}}}$} & \multirow[b]{2}{*}{ Disaster kind } & \multirow{2}{*}{$\begin{array}{c}\text { Disaster } \\
\text { power }\end{array}$} & \multicolumn{5}{|c|}{ the cities vulnerability disaster } & \multirow[b]{2}{*}{ Notes } \\
\hline & & & $\begin{array}{c}\mathrm{V} . \\
\text { Strong }\end{array}$ & Strong & Mid & Weak & $\begin{array}{c}\mathrm{V} . \\
\text { week }\end{array}$ & \\
\hline \multirow{7}{*}{ 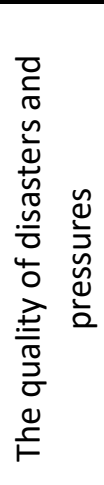 } & Economic crises & & & & & & & \\
\hline & Revolutions & & & & & & & \\
\hline & Terrorism and armed civil wars & & & & & & & \\
\hline & Epidemics and diseases & & & & & & & \\
\hline & Earthquakes - Volcanoes & & & & & & & \\
\hline & Landslides & & & & & & & \\
\hline & Other (to be determined) & & & & & & & \\
\hline
\end{tabular}

Table 2. Assessment of disasters and risks facing the city of San Hajar

For assessment, Table (2) was added all city elements to ease evaluation based on standards and specifications for resilience of cities.

\begin{tabular}{|c|c|c|c|c|c|c|c|c|c|}
\hline \multirow{2}{*}{$\stackrel{\xi}{\underline{a}}$} & \multirow{2}{*}{ Element } & \multirow{2}{*}{$\begin{array}{l}\text { Sta. } \\
\text { W }\end{array}$} & \multicolumn{5}{|c|}{ Evaluation based on flexibility } & \multirow{2}{*}{$\begin{array}{c}\text { Ach. } \\
\text { W }\end{array}$} & \multirow{2}{*}{ Notes } \\
\hline & & & Res & Bal & Cri & Frag & Det & & \\
\hline \multirow{4}{*}{ 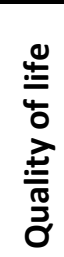 } & 1- Housing & & & & & & & & \\
\hline & 2-Services & & & & & & & & \\
\hline & Education & & & & & & & & \\
\hline & Health & & & & & & & & \\
\hline
\end{tabular}


Al-Sayed, S.H.;

ElSayed, Y.A.;

Gadou, S.S.
The application of resilience planning concepts as a tool for Assessment and evaluating Egyptian urban communities to achieve resilience after disasters

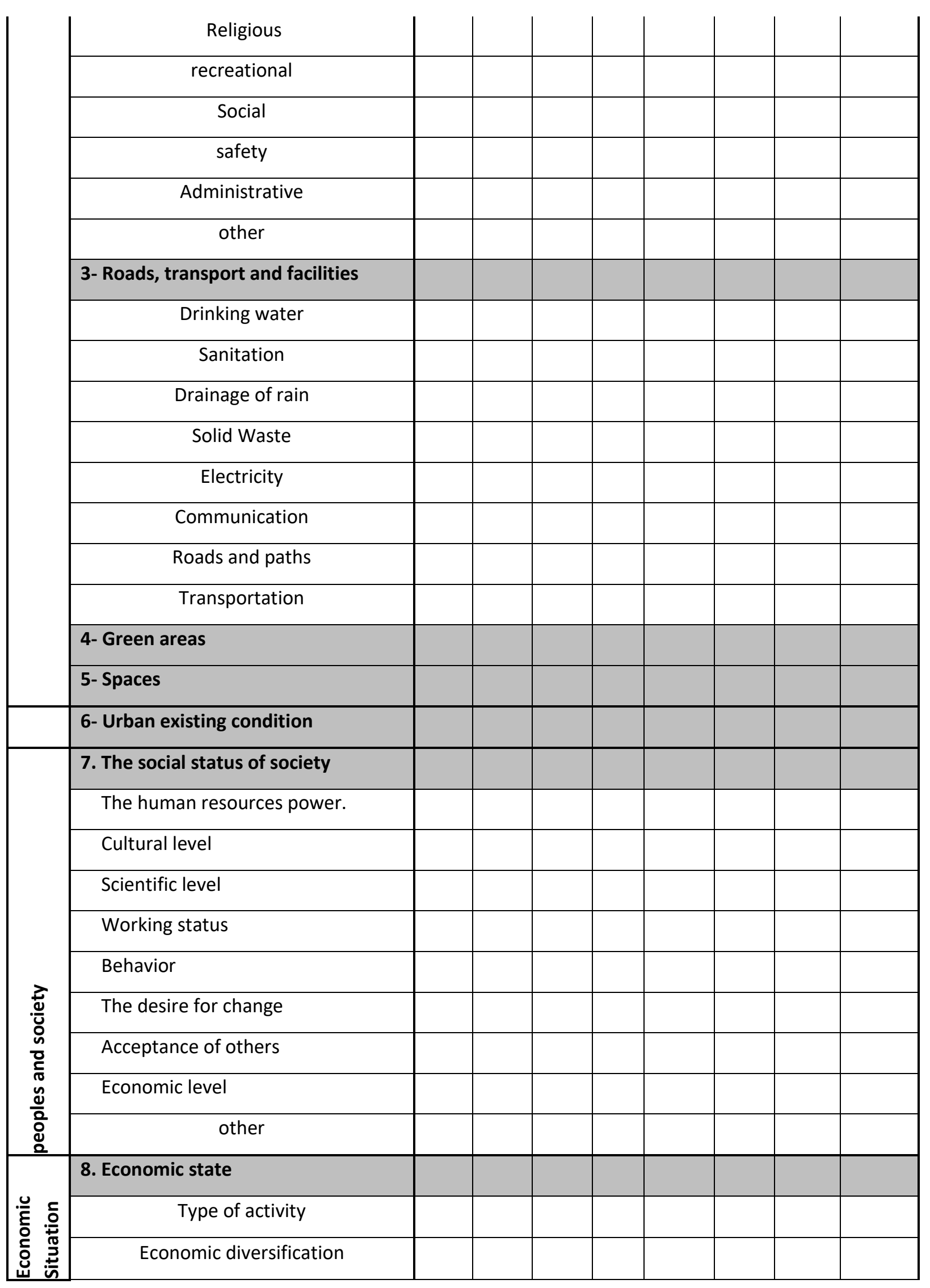




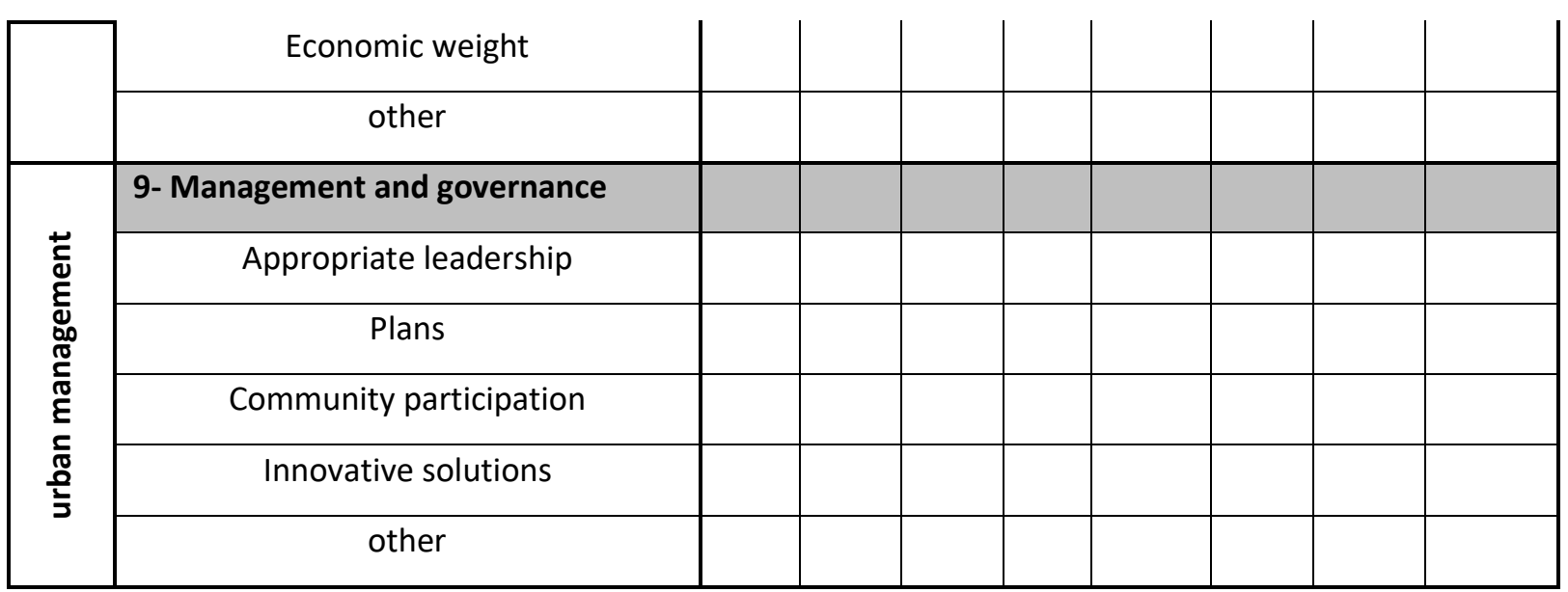

Table 3. the assessment of urban agglomerations based on the criteria and principles of resilient cities

The work of the strategic plan for the city has been completed in 2020 and is being approved to work on its basis. By studying the current conditions of the city, the following was found:

The city is dominated by residential uses by $32 \%$, and community services represent $8 \%$, including educational services (primary, preparatory and secondary), and simple health services where there is no general hospital or any hospital with a family, and there is a youth center that is It is built only without playgrounds or open spaces, and there are religious and administrative services, a post office, and finally a modern branch of the Faculty of Archeology (Zagazig University). The road network represents its percentage of 30\%, Empty land 18\% including Agriculture pockets, and utilities represents $1.4 \%$. the city has many problems as services and utilities shortage and traffic gams in the entrance and city center. By studying the conditions of the facilities, it was found that there is a shortage in the per capita share of drinking water (60 liters/person/day) which is less by $60 \%$, as the per capita, and there is no sanitation network for about $65 \%$ of the city, while electricity and communications are well available, except for the extensions or New urban areas on the outskirts of the city, which was built in the absence of planning after the January 2011 revolution.

When preparing the strategic plan, many small urban areas were added to the city Cardone 71 acres including 45 acres of agricultural pockets to be used to make the city resilience by adding residential uses and basic services or to add roads and utilities to serve the city.

\section{Applying the evaluation form to the city of San El-Hajar}




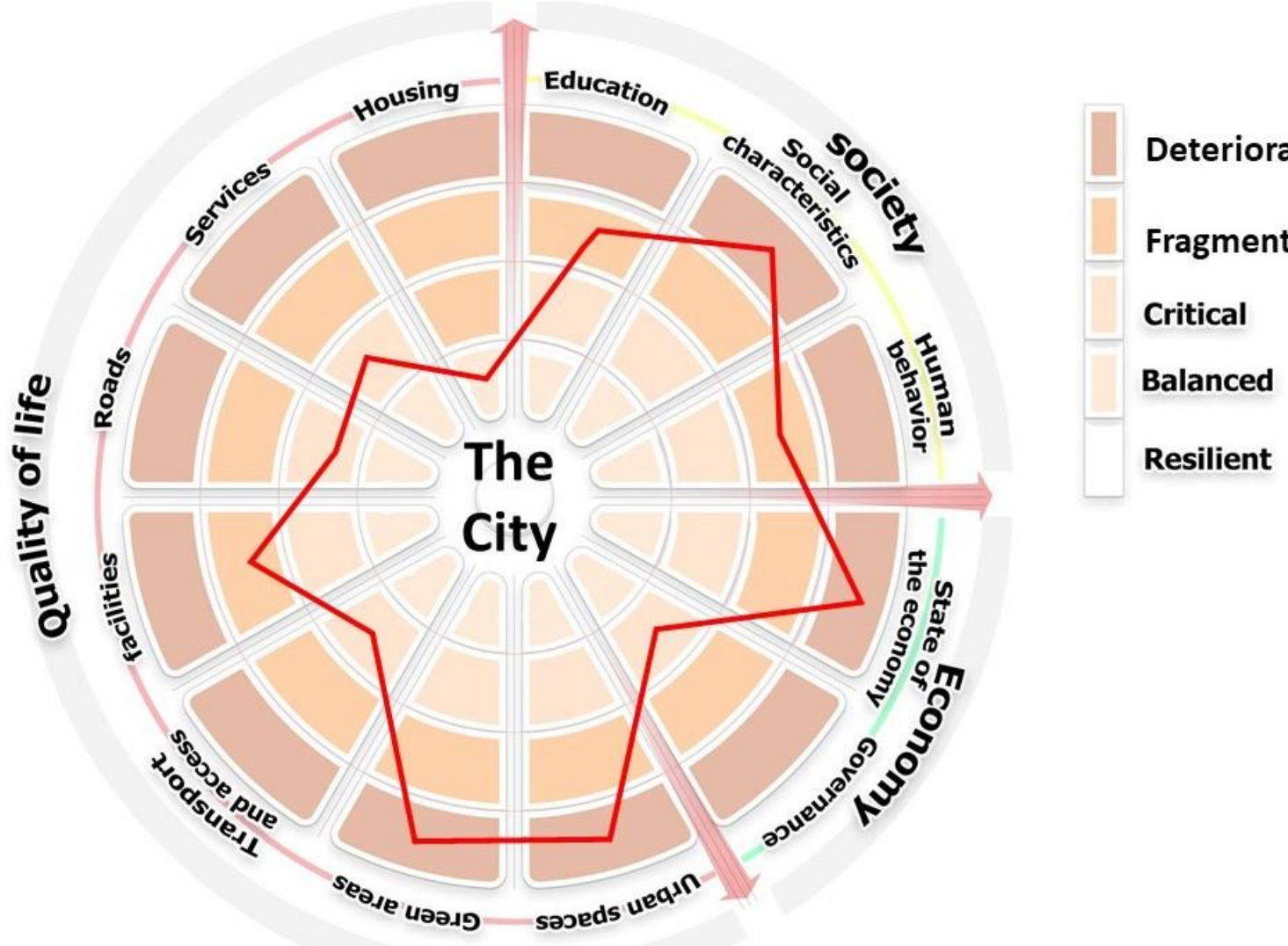

Figure No. (3) Applying city assessment form to comply with the resiliency requirements for San El-Hagar

By applying the city assessment form to comply with the resiliency requirements. (3) found the following.

- The city is characterized by high flexibility in the field of housing, as there are $25 \%$ vacant housing that represents a housing stock that accommodates high ratio of current and future needs of the population.

- The status of the city is critical in the field of educational and administrative services, and is fragile and deteriorating in the field of other services, and water and sewage utilities too, and it is critical in the field of transportation and roads.

- The city suffers from major economic problems, as unemployment increases to be (18\%), and the economic structure suffers from deterioration due to the collapse of one of the leading companies as (San El-Hagar Company) which sale of its lands and assets to pay the salaries for employees as well as the collapse of projects as breeding and exporting of poultry and rabbit meat.

- The environment is still clean because the city is surrounded by agricultural lands, with the exception of the southern part, which suffers from some environmental problems as a result of the contiguity with the fish farms that caused problems for the nearby buildings.

- The city does not contain spaces or green areas.

- The cultural and scientific level and human capabilities are good, as most of the population of the young age groups are educated and lead a simple, good social life. The poverty rate is $25 \%$ (less than the average in the governorate) 
The city's assessment has been signed on Diagram, the basic guidelines for evaluating the city and its components and achieving the requirements of a resilient city as in Figure (3)

- It is worth noting that the city is not exposed to natural hazards except for desertification of agricultural lands and encroachment of buildings on it, which makes the city lose a significant economic resource, and the spread of solid waste on canals and drains.

Through Figure No. (3), the analysis and study were carried out on how to address the shortcomings and to transform the city to resilience city, where the following was done: -

- For the expected population: an area of 35 acres of housing was provided to accommodate 8750 until 2032, with a density of 250 person/ acre.

- Concerning services: Several sites have been proposed to provide a number of primary preparatory, and - secondary classes, with the suggestion of a technical school or institute or college specialized in archeology. As for health services, an addition has been proposed $5000 \mathrm{~m} 2$ for a hospital 150 bed to serve the city and surrounding villages. In addition, consideration has also been given to providing missing services for youth as sports and recreational, administrative and religious services.

- Economy of the city: It was proposed to increase the city's economic capabilities by providing some light industrial and hand crafts activities that depend on tourism, especially next to (Tell San Al-Hajar - Tanis), where the residents of the village of Tal San Al-Hajar can be encouraged to host tourism for daily accommodation and to create a three or four star hotel and commercial services for handicrafts. Clearing canals and drains and dig wells to preserve agricultural land, which is forbidden to encroach on

- Roads and facilities: the efficiency of the road and transportation network is increased by expanding the main and community roads and creating a station for the city on its southern borders, and the facility's capabilities are increased to match the reasonable rates of potable water and sanitation, as well as the extension of electricity networks throughout the city.

Through these treatments, it can transform the city of San Hajar to a resilience city, especially with the increase in the capabilities of facilities and roads, and the provision of the necessary services at natural rates and raising the efficiency of each of them. 

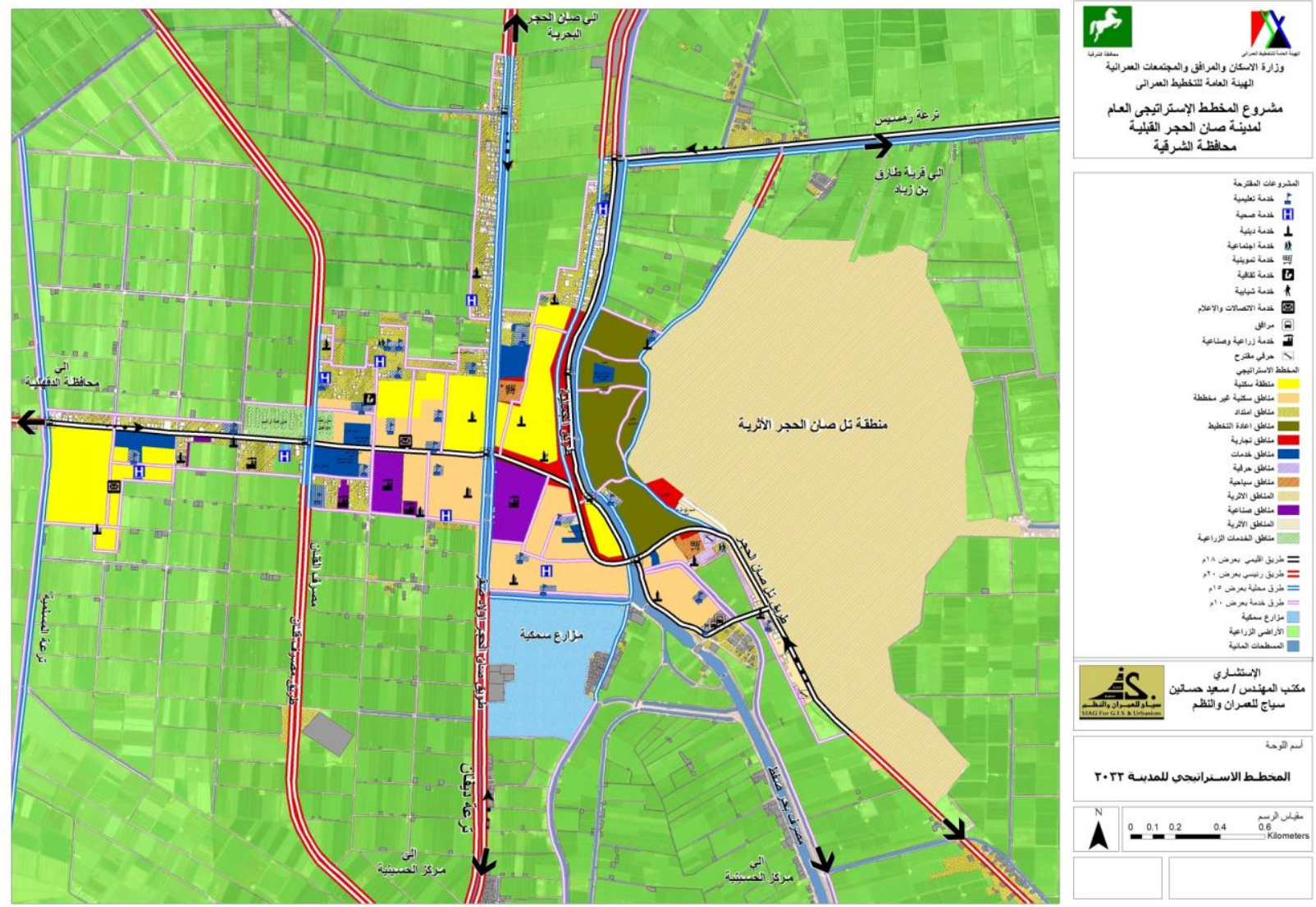

Figure (4) the Resilience strategic plan of San El-Hagar city

\section{Conclusion and recommendations}

- Applying resilience city principles and foundations to existing cities by identifying the extent of the compatibility of the city's elements with the basic guide lines of the resilience city, then evaluating and then taking the appropriate decision to transform it into a resilience city.

- The city can be resilient only when it fulfills the minor limits of quality of life, while providing an additional range in its ratios that can be consistent with the risks that faced the city.

- City administration and local government are effective management to maintain the resiliency of the city and even achieve its requirements. Therefore, effective administrative elements must be chosen with extensive and innovative experiences in the social, economic and administrative fields while providing a strong information base that helps them in making decisions.

- The accurate study and analysis to the existing cities that is followed by the evaluation on the basis of resiliency helps in applying and realization of the principles of the resilient city.

\section{References}

100 RESILIENT CITIES, THE ROCKEFELLER FOUNDATION, 2017, Cities taking Action- HOW THE 100RC NETWORK IS BUILDING URBAN RESILIENCE, USA

World Bank (GFDRR), 2017, RESILIENT CITIES - Reducing urban risk. 
Al-Sayed, S.H.;

ElSayed, Y.A.;

Gadou, S.S.
The application of resilience planning concepts as a tool for Assessment and evaluating Egyptian urban communities to achieve resilience after disasters

Dr. Niki Frantzeskaki, Lead Expert, Resilient Europe, 2016. URBAN RESILIENCE- A concept for cocreating cities of the future- - DRIFT, Erasmus University Rotterdam, The Netherlands - Europe Union.

Ayyoob Sharifi1, Yoshiki Yamagata, 2014, Resilient urban planning: Major principles and criteria, The 6th International Conference on Applied Energy ICAE - Published by Elsevier Ltd

Rebecca Laberenne P.E, 2016, 100 Resilient Cities- Program Overview- and Case Studi es.ICC Global Connections Day- Kansas City.

World Bank Group's, 2017, Evolving Approach Paper -Towards Urban Resilience -(2007-2017, USA

DIMSUR TECHNICAL CENTRE FOR DISASTER RISK MANAGEMEN, 2014 SUSTAINABILITY AND URBAN

RESILIENCE IN SOUTHERN AFRICA -BASELINE STUDY -Working Document for Discussion

100 RESILIENT CITIES, THE ROCKEFELLER FOUNDATION, 2019 Resilient Cities, Resilient Lives- Learning from the 100RC Network, USA.

100 resilient cities program, 2019, SAFER AND STRONGER CITIES STRATEGIES FOR ADVOCATING FOR FEDERAL RESILIENCE POLICY, USA

Dr. Mohammed Mahdi Hussein, 2016, The Effect of the Resilient Urban Form on the Resilience of Cityمجلة الهندسة والتكنولوجيا، الدجلد 34 ،/الجزء (A)، 487 - 501- العدد.

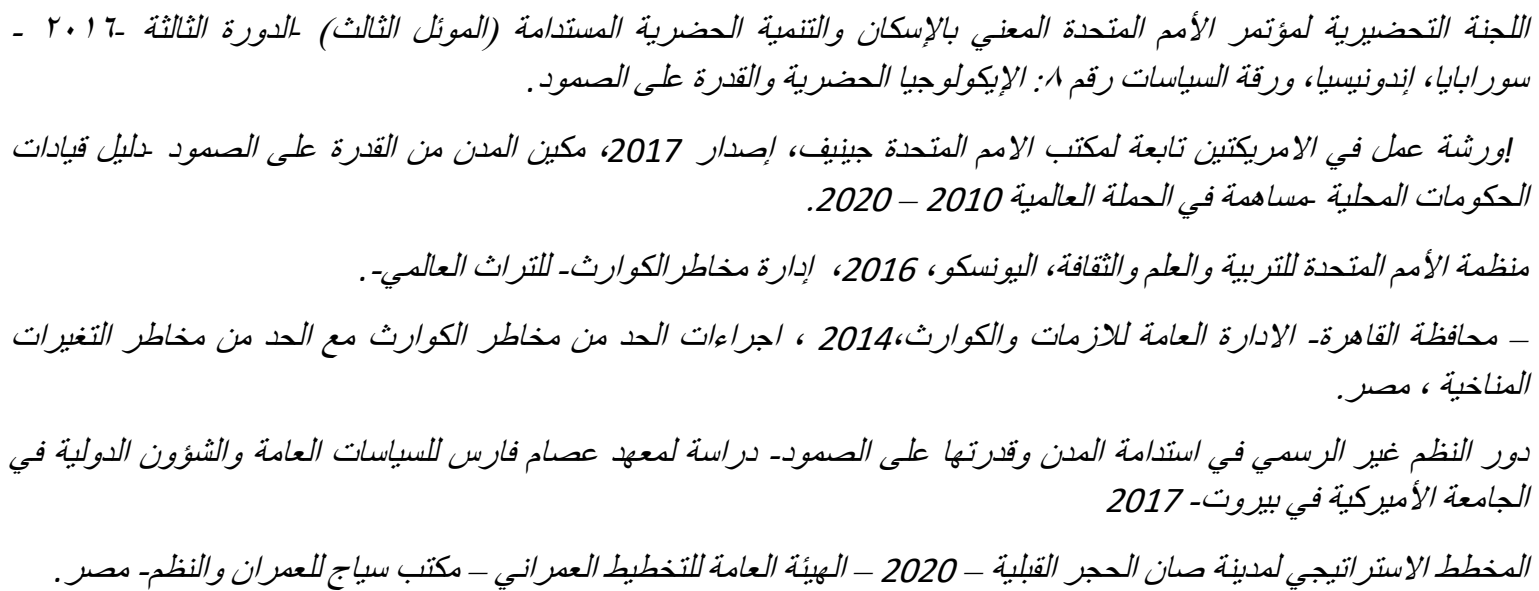

https://www.emergency-live.com/ar/civil-protection/urban-resilience-resilient-cities-plug-in-totechnology-for-response-and-recovery/

https://planningforhazards.com/resilience-planning

https://www.researchgate.net/publication/321609156_A_framework_for_urban_resilience_planning 